\title{
educação

\section{Opção sexual ou orientação sexual? A compreensão de professores de um curso de Medicina sobre sexualidade}

Yalin Brizola YARED

Universidade do Sul de Santa Catarina, Brasil

Sônia Maria Martins de Melo"

\author{
Universidade do Estado de Santa Catarina, Brasil
}

\begin{abstract}
Este artigo apresenta parte de resultados de um estudo que investigou a compreensão de docentes de um curso de Medicina sobre a dimensão humana da sexualidade para desvelar processos de educação sexual vividos numa proposta de currículo inovador. A pesquisa foi norteada pelo paradigma do materialismo histórico dialético que utiliza o método dialético para análise da realidade. Os instrumentos de coleta compreenderam questionários e entrevistas. A análise de conteúdo desvelou contradições na prática pedagógica, que representa vivências ancoradas na vertente médico-biológica somada ao paradigma da medicina científica. Como resultado, registrou-se o uso ainda constante das palavras "opção sexual", "escolha sexual" e "homossexualismo", o que sugere a compreensão da diversidade por abordagens biológicas, patologizantes e reducionistas. O fortalecimento da formação continuada e permanente dos docentes torna-se urgente e necessária. Contudo, as contradições também apontam para um curso vivo, dinâmico e em transição paradigmática, onde há possibilidades de se vivenciar com plenitude pedagógica processos de educação sexual numa abordagem emancipatória.
\end{abstract}

Palavras-chave: Graduação em Medicina; Currículo integrado; Formação médica; Educação sexual emancipatória; Formação de professores

INTRODUÇÃO: A PRESENTANDO O CONTEXTO

O presente artigo expõe parte de resultados de pesquisa de doutorado desenvolvido no Programa de Pós-Graduação em Educação da Universidade do Estado de Santa Catarina/ FAED/UDESC e no contexto do Grupo de
Pesquisa EDUSEX - Formação de Educadores e Educação Sexual UDESC/CNPq. A referida tese $^{1}$ investigou a compreensão de docentes, que atuam num curso de graduação em Medicina de uma universidade comunitária brasileira, sobre a dimensão humana da sexualidade, para desvelar processos de educação sexual vividos em uma proposta de inovação curricular.

\footnotetext{
${ }^{1}$ A pesquisa (Yared, 2016) contou com os seguintes apoios financeiros: bolsa PROMOP/UDESC, de agosto/2012 a abril/2013; bolsa CAPES/DS, de maio/2013 a julho/2016; e bolsa CAPES/PDSE durante doutorado sandwich em Portugal entre outubro/2014 e julho/2015.
} 
Dois fatores principais instauraram a necessidade e urgência da pesquisa: primeiramente, a justificativa refere-se ao espaço escolar, pois é nele que constantemente se recorre a profissionais da área da saúde, principalmente da área médica, para ministrar palestras sobre sexualidade e educação sexual aos seus estudantes. Contudo, pesquisas anteriores registram que estas abordagens fundamentam-se ainda, em grande parte, em paradigmas repressores e reducionistas de sexualidade, especialmente pela vertente médico-biologista (Melo \& Pocovi, 2008; Nunes, 1996; Santos \& Bruns, 2000; Yared, 2011). Depois, justifica-se pela vivência da primeira autora como docente de um curso de graduação em Medicina.

Relatamos que o referido curso de graduação em Medicina representa um ambiente educacional completamente diferenciado do habitual. Organiza-se em um currículo integrado, orientado por competências, desenvolvido $100 \%$ por meio de metodologias ativas e constituído por um corpo docente interdisciplinar e multiprofissional. Apresenta um Projeto Pedagógico de Curso ${ }^{2}$ fundamentado em Paulo Freire e John Dewey, que propõe inovações pedagógicas como proposta de ensino e aprendizagem aplicada à vida, além de privilegiar explicitamente a formação humana e científica dos/as futuros/ as médicos/as e cidadãos e cidadãs para que sejam capazes de análise crítica, autônoma e efetivo compromisso com a saúde. Foi criado no início da década de 2000, atendendo às recomendações das Diretrizes Curriculares Nacionais (Brasil, 2001, 2014). A necessidade de sua abertura justificou-se, dentre outros motivos, por cumprir o Programa Nacional de Incentivo a Mudanças Curriculares nos Cursos de Medicina e em razão das discussões sobre os saberes médicos realmente necessários à formação dos profissionais generalistas, "que atendam às reais necessidades da população, constituindo-se em uma mudança paradigmática para a saúde" (Projeto Pedagógico do Curso [PPC], p. 6).

Nasceu, assim, uma proposta de curso que sustenta um projeto de uma educação progressista, problematizadora, dialógica, reflexiva, crítica, centrada no estudante e no seu que-fazer enquanto ser humano, como caminho de uma educação libertadora libertação autêntica (Freire, 2005). Assim, foi definido um currículo integrado e orientado por competências, onde as relações são mediadoras no processo de ensinoaprendizagem e docentes e discentes, sujeitos nesse processo. Dentre outras mudanças, também propôs a "aprendizagem significativa, utilização de metodologias ativas de ensino e aprendizagem, cenários reais integrados, aplicação de diferentes modalidades de avaliação em processo" (PPC, p. 24).

Sendo assim, optou-se por trilhar um caminho na contramão de uma educação bancária e conteudista (Freire, 2005); o curso organiza-se em Unidades Educacionais e não em disciplinas, o que representa a busca da superação da fragmentação do conhecimento. As Unidades Educacionais são trabalhadas a partir de cenários de ensino e aprendizagem, que são: as Unidades Sistematizadas (Tutoria e Conferência), a Unidade de Prática de Saúde na Comunidade (PSC), a Unidade Eletivo e a Unidade Internato. Cada cenário compõe seus Planos de Unidades, que integram os diferentes saberes e tarefas previstas para cada ano. Ou seja, optou-se por um caminho que favoreça a mudança paradigmática educacional, onde o processo de ensino-aprendizagem é ativo e processual,

\footnotetext{
${ }^{2}$ O Projeto Pedagógico do Curso (PPC) de Graduação em Medicina, datado de 2012, não é identificado para manter o anonimato da universidade.
} 
problematizador, centrado no estudante e no desenvolvimento de sua autonomia, visando a mudança do comportamento humano, no entendimento de ser humano integral. E, em sua missão, objetivos e perfil profissiográfico, encontramos explícito o entendimento de seres humanos na sua inteireza - portanto, sempre sexuados, erotizados e sensualizados, incluídos aí seus atores e autores. $\mathrm{E}$ isso se expressa e vem ao encontro da contemplação intencional da dimensão sexualidade humana, que está prescrita explicitamente na Unidade Educacional do $3^{\circ}$ ano do curso.

Destarte, ao experienciar a contemplação viva do fenômeno (Triviños, 2012) e partindo do entendimento empírico, a primeira autora percebeu pistas da perpetuação de paradigmas repressores e reducionistas de sexualidade, especialmente pela vertente médico-biologista (Nunes, 1996) nas práticas didático-pedagógicas de docentes do curso, o que instigou o processo de investigação.

\section{BREVE EXPLICITAÇÃO DOS PRESSUPOSTOS TEÓRICOS}

Integrantes do Grupo de Pesquisa EDUSEX, consolidado há 30 anos, as autoras do presente artigo - membro e líder, respectivamente - desenvolvem pesquisas que visam contribuir para a formação inicial e continuada de professores/as fundamentada no paradigma emancipatório de educação sexual. Compreendemos que a dimensão da sexualidade encontra-se na base das expressões humanas, constituinte da condição ontológica, visto que não é uma simples expressão biológica, pois os seres humanos têm a consciência do prazer e do desejo intencional, transformando-a também em atividade erótica e sensual. Nesta perspectiva, afirmamos que o ser humano não "tem" sexualidade, ele "é" sexualidade (Cabral, 1995). De acordo com a Organização Mundial da Saúde (OMS), a sexualidade é

parte integral da personalidade de todo ser humano, é construída por meio da interação entre os sujeitos e as estruturas sociais. A sexualidade é uma energia que nos motiva a procurar amor, contato, ternura e intimidade, que se integra no modo como nos sentimos, movemos, tocamos e somos tocados, é ser-se sensual e ao mesmo tempo sexual; ela influencia pensamentos, sentimentos, ações e interações e, por isso, influencia também a nossa saúde física e mental. (OMS, 1975, cit. em Melo, Pocovi, Carvalho, Mendes, \& Santos, 2011, p. 30)

Afirmamos que a sexualidade "é uma dimensão indissociável do fato de sermos humanos" (Melo et al., 2011, p. 23), em qualquer momento de nossas vidas e em qualquer ambiente, inclusive nos ambientes escolares - incluídas aí, as escolas médicas. Na sociedade em que vivemos, a sexualidade, seus discursos e práticas perpassam todos os âmbitos da vida; desse modo "somos seres humanos sempre sexuados ao estabelecermos as relações sociais, na produção do nosso modo de vida, ao construirmos nossa história da sexualidade ao mesmo tempo em que ela nos constrói” (Melo et al., 2011, p. 24).

A dimensão sexualidade é inseparável do processo sócio-histórico da constituição de vida dos seres humanos. Como sujeitos sexuados no mundo, entendemos que, ao nos relacionarmos uns com os outros, sempre está aí incluída essa dimensão, inseparável do existir humano. Assim, compreendemos que a educação é um processo permanente e contínuo na relação entre seres humanos. Como afirma Freire (2005), "ninguém educa ninguém, ninguém educa a si mesmo, os homens se educam em comunhão, mediatizados pelo mundo" (p. 79). Desse modo, "os seres humanos, sempre 
sexuados, estão em permanente processo de Educação com os outros seres no mundo", logo, "processo esse também sempre de Educação Sexual" (Carvalho, Mendes, Melo, \& Santos, 2012, p. 48). Desse modo, a vida é sempre um processo de educação sexual entre os seres humanos. E educar também é "construir redes de significações culturais e comportamentos padronizados de acordo com os códigos sociais vigentes" (Nunes, 2005, p. 30). Portanto, somos sempre, "queiramos ou não, saibamos ou não, educadores sexuais uns dos outros" (Carvalho et al., 2012, p. 48). E, nesse sentido, qualquer processo educativo, seja formal, não-formal ou informal, é sempre sexuado (Melo et al., 2011).

Na prática educacional, incluída aí a educação superior, tem-se evidenciado as influências das vertentes repressoras e reducionistas de sexualidade. Embora novas concepções de ensino com métodos diferenciados e com apoio da modernização tecnológica de informações estejam sendo incorporadas em projetos pedagógicos, o que ainda se encontra são características preponderantes de omissão, de controle e/ou de repressão vivenciadas pelos/as estudantes, professores/as e/ou funcionários/ as, destacando-se a vertente médico-biologista (Carvalho et al., 2012; Figueiró, 2006; Melo \& Pocovi, 2008; Santos \& Bruns, 2000; Silva, 1997, 1998; Yared, 2011, 2016).

A vertente médico-biologista descrita por Nunes (1996) representa a compreensão da dimensão da sexualidade "numa perspectiva reducionista, a partir da interpretação médico-biológica da condição humana" (p. 139), inclusive por meio de uma compreensão e instrução higienista. Nessa ótica, o ser humano é fragmentado, dicotomizado e analisado como um conjunto de funções e aparelhos com propósito biológico para a sobrevivência ou para a evolução naturalista. Nunes (1996) salienta que a "interpretação biologista fundamenta-se numa antropologia reducionista que faz da evolução natural uma única lei, radicada na interpretação darwinista ou cientificista do século XX" (p. 139). Daí o enfoque procriativo, a negação do prazer e o entendimento do ato sexual como exclusivo para procriação, dado a sexualidade ser reduzida ao "instinto", ou seja, a uma força natural do ser humano. Nas décadas de 70 e 80 do século $\mathrm{XX}$, as abordagens fundamentadas nesse paradigma proliferaram e tiveram sucesso, pois "o discurso médico, matriz da interpretação biologista, reforça o mesmo discurso conservador e institucional presente até então na sociedade brasileira" (Nunes, 1996, p. 140). Nas palavras de Nunes (1996):

O discurso médico associa-se a esta concepção biologista-reprodutiva, tratando a sexualidade como um amontoado de generalizações biológicas, descritivas, funcionalistas e profiláticas, propondo uma profilaxia de um conhecimento absolutamente descritivo e medidas restritivas e indicativas de tratamento médico, até patológico. (p. 141)

Consequentemente, podemos notar que em muitos espaços ainda há o predomínio da vertente médico-biologista em intervenções sobre a sexualidade (Figueiredo, 2015; Freitas, 2016; Oliveira, 2007; Silva, 1997, 1998; Yared, 2011; Yared, Melo, \& Vieira, 2015), priorizando seus aspectos higienistas em detrimento de outros aspectos que também são próprios por se tratar de uma dimensão humana. Silva (1998) já apresentava preocupação com a formação dos profissionais médicos e com a importância de compreendermos por quem e como estão sendo formados os profissionais da Medicina, no que se refere especificamente à temática da sexualidade, seja pelo papel social legitimado que esses profissionais têm sobre a questão, seja porque ainda são aqueles especialistas que as escolas 
consideram autorizados em educação sexual. Assim, intervenções pautadas nessa vertente representam, muitas vezes, uma alternativa de coibir práticas sexuais tidas como promíscuas, "permissivas e aparentemente perigosas" (Nunes, 1996, p. 142), além de relacionar diretamente à proliferação de doenças. Não se trata, nesse sentido, de um processo de educação libertária em sexualidade, que visa à consciência racional, crítica-reflexiva, para o desenvolvimento da autonomia e de uma vida sexual responsável, prazerosa e feliz, mas sim de um "amedrontamento institucional" (Nunes, 1996, p. 142).

A sociedade atual - lembrando-se que dela não se exclui a comunidade acadêmica -, ancorando-se, em sua maioria, numa matriz heterossexual, delimita padrões/regras a serem seguidos. Existem muitas formas de viver os gêneros e a sexualidade; porém, muitas ações acabam norteadas pelo padrão dito adequado/legítimo/normal de feminilidade, de masculinidade e de projeção dos desejos, o que prontamente define a heterossexualidade como a única forma sadia de os sujeitos vivenciarem a sua sexualidade. Logo, "a heterossexualidade é concebida como natural e também como universal e normal" (Louro, 2007, p. 17), fato este que se apresenta ainda fortemente enraizado na cultura brasileira. Um dos reflexos desse enraizamento é a constante violência e assassinato na comunidade de Lésbicas, Gays, Bissexuais, Travestis e Transexuais (LGBT) ${ }^{3}$, fruto do preconceito sobre a riqueza da diversidade sexual e de gênero existente em nosso país.

Destarte, compreender a sexualidade a partir do paradigma emancipatório está representado pela vertente dialética e política de Nunes (1996). Representa um processo de educação sexual intencional pautado conscientemente numa concepção dialética e numa perspectiva política por meio de um discurso que vise à emancipação dos sujeitos, à promoção dos Direitos Sexuais (World Association for Sexual Health [WAS], 2014) enquanto Direitos Humanos universais e fundamentais e à consciência crítica da complexidade desse processo que é dinâmico, ou seja, que está sempre em movimento na busca da superação da contradição e alienação. Assim, essa vertente expressa

um novo paradigma de entender a sexualidade, que denominamos emancipatório e humanista. Emancipatório porque supõe uma profunda reflexão sobre a sexualidade de modo a elucidar suas contradições históricas, discutir suas bases antropológicas, investigar suas matrizes sociológicas e identificar suas configurações políticas... de modo a tornar claras sua vinculação com relações de poder vigentes. (Nunes, 1996, p. 227)

Portanto, fomos buscar no curso pesquisado a compreensão dos/as docentes sobre a dimensão humana da sexualidade e suas vivências em uma inovação curricular. Entendemos que torna-se imprescindível, em uma proposta curricular que propõe transformações paradigmáticas para a formação médica, uma abordagem para além da concepção biológica em sexualidade. Logo, que também leve em conta os fatores psicossociais, históricos e culturais do desenvolvimento humano, capaz de superação de paradigmas reducionistas, repressivos e patológicos, promovendo, desta forma e intencionalmente, processos emancipatórios de educação sexual (Nunes, 1996; Santos \& Bruns, 2000; Silva, 1997, 1998; Yared, 2011,

\footnotetext{
${ }^{3}$ Segundo relatórios publicados pela associação Grupo Gay da Bahia, presidida pelo prof. Dr. Luiz Mott (UFBa), o Brasil está no ranking mundial de crimes motivados pela homo/transfobia à comunidade LGBT.
} 
2016). Nesse sentido, questionamo-nos: como os/as docentes percebem a temática da educação sexual nesse curso de Medicina?

\section{MOVIMENTOS METODOLÓGICOS}

De natureza qualitativa, o estudo no contexto do Grupo EDUSEX configurou-se fundamentalmente em uma pesquisa norteada pelo paradigma filosófico do materialismo histórico dialético - entendido como princípio para observação e compreensão do mundo, para análise e explicação da realidade, bem como das relações humanas, estas sempre sexuadas, como produtos e produtoras nas transformações sociais. O termo "movimentos metodológicos" pauta-se em nossas escolhas teórico-metodológicas. Amparadas por Netto (2016), compreendemos que, no método dialético de análise da realidade, o conhecimento é uma reprodução do mundo das ideias, onde o pesquisador "tem como objetivo reproduzir idealmente o movimento efetivo real do objeto" (s/p). Logo, o/a pesquisador/a não acrescenta nada ao objeto, ele/a "extrai", recepciona suas categorias constituintes. $\mathrm{O}$ pesquisador recebe as regularidades, as categorias, as leis do objeto em estudo. O movimento é do objeto. Portanto, pesquisar a realidade a partir do método dialético é captar a reprodução ideal do movimento real do objeto.

O projeto de pesquisa foi aprovado pelo Comitê de Ética na Pesquisa ${ }^{4}$. A recolha dos dados fundamentou-se em Stake (2012) e Triviños (2012) e recorreu a diferentes recursos, como o questionário e a entrevista semiestruturada gravada na forma de áudio. Estes instrumentos e técnicas foram considerados os mais adequados para se realizar a busca pela compreensão dos sujeitos sobre o fenômeno em estudo e todas as informações sofreram triangulações durante a análise dos dados.

A construção dos instrumentos de coleta foi norteada por quatro dimensões que representaram a busca da compreensão dos/as docentes sobre o prescrito e o vivido no Curso de Graduação em Medicina: 1) compreensão do PPC; 2) como os sujeitos compreendem seu caminho profissional; 3) como os sujeitos compreendem a dimensão sexualidade; e 4) como os sujeitos compreendem o processo de educação sexual. As várias questões dos instrumentos de coleta foram pautadas em Vieira e Vieira (2005).

O questionário foi elaborado na plataforma do Google Forms. Era composto por vinte e sete (27) questões, organizadas em cinco (5) blocos: identificação pessoal; formação profissional; atuação docente; prática pedagógica; e situações da vida real. Após finalizado, foi enviado para três especialistas da área - duas brasileiras e um português -, que o validaram para o uso na coleta de dados. Por sua vez, o roteiro da entrevista semiestruturada foi composto por 13 questões norteadoras e organizadas em três blocos: trajetória profissional e acadêmica; atuação no curso; educação sexual.

Apresentava-se, dentre a população participante, um universo de 119 docentes. Todo o colegiado foi convidado, durante sete meses $^{5}$, para participar da pesquisa, tanto por questionário online como impresso.

${ }^{4}$ CEP/UDESC, Parecer no 848.757.

\footnotetext{
${ }^{5}$ Durante dois meses, a participação apenas via e-mail, com questionário online, foi tentada. Houve poucas participações, uma vez que as pessoas não respondiam a e-mails. Então, optou-se pelo questionário impresso. Durante cinco meses, a primeira autora esteve presente semanalmente no curso de Medicina, para entregar e recolher questionários, além de participar de duas reuniões de colegiado, falando da importância da pesquisa. Também houve apoio da coordenação e do núcleo docente estruturante do curso, que estimulavam os/as docentes a participarem.
} 
Como resultado, 34 docentes responderam ao questionário e, dentre estes, 15 voluntariaramse para realizar a entrevista. Especificamente, dentre os/as 15 docentes voluntários/as, destacamos: 12 mulheres e três homens, sendo dois bacharéis, seis especialistas, cinco mestres e duas doutoras; mais especificamente, nove médicos/as e seis não médicos/as. Todos/as assinaram o Termo de Consentimento Livre e Esclarecido (TCLE) e todas as entrevistas foram transcritas e enviadas por e-mail para aprovação. Nessa etapa, tornou-se necessário estabelecer seus pseudônimos. Decidimos buscar por nomes de Deuses, Deusas e seres da mitologia grega relacionados à área médica, da saúde e da saúde sexual. Com o propósito de garantir ao máximo o anonimato dos/das participantes entrevistados/as, determinámos que os sujeitos seriam mencionados apenas por seus pseudônimos e relacionados à informação de "Med" para docentes médicos/ as e "Não med" para docentes não médicos/as. A análise de conteúdo foi pautada em Triviños (2012) e Bardin (2014) com complementos de Moraes (2003). Como resultado da pesquisa em sua totalidade, alcançamos o registro de uma categoria emergente (Moraes, 2003): a ambiguidade. Mais especificamente: a ambiguidade dos sujeitos imersos numa mudança paradigmática - ainda latente e, talvez, se fortalecendo. Ou seja, nas análises, durante a busca da compreensão dos/as docentes sobre o prescrito (PPC) e o vivido no curso, foram desvelados indicadores de categoria - ou unidades de significado, para Moraes (2003) - que apontaram para comportamentos ambíguos no mundo vivido dos/as docentes. E um desses indicadores representou a ambiguidade na compreensão da vivência da sexualidade, ao expressarem constantemente o termo "opção sexual" ao invés de orientação sexual - o que apontou para uma possível compreensão imprecisa, insegura e ambígua da vivência da sexualidade entre ser uma escolha ou ser um direito. Na compreensão de educação sexual emancipatória, a dimensão sexualidade é inerente ao humano; portanto, somos todos sexuados e vivenciamos nossos desejos de várias formas, no conceito chamado de “orientação sexual". Como afirma Cardoso (2008), o conceito de orientação sexual pode variar conforme área ou autor, mas, "na maioria das vezes, esse conceito está relacionado ao sentido do desejo sexual: se para pessoas do sexo oposto, do mesmo sexo ou para ambos" (p. 73).

Neste artigo, apresentamos um recorte da totalidade pesquisada em Yared (2016). Explicitaremos, a seguir, a análise deste indicador de categoria expressivo em vários docentes: o uso constante da expressão "opção sexual", ao referirem-se à orientação sexual dos sujeitos - registrado principalmente durante as respostas às questões que abordavam Situações da Vida Real (questões $n^{\circ} 20^{6}, n^{\circ} 21^{7}$ e $n^{\circ} 22^{8}$ do questionário) e durante as entrevistas, ao

\footnotetext{
${ }^{6}$ Questão n 20: “Em uma escola pública, os estudantes do $9^{\circ}$ ano (antiga $8^{\text {a }}$ série) apresentam muitas dúvidas sobre sexualidade; além de fazerem constantes brincadeiras de 'mau gosto' com os colegas e com os professores, também fazem desenhos pornográficos nas carteiras. Os/as professores/as têm dificuldades de trabalhar esse tema junto aos estudantes, dizem que estão muito 'precoces' e que não levam o assunto a sério. Deste modo, a diretora resolveu pedir ajuda à unidade de saúde do bairro, convidando um médico ou uma médica para fazer uma palestra sobre sexualidade para todos os estudantes do $9^{\circ}$ ano. Na sequência, o profissional médico encaminhou seus estudantes do curso de Medicina da sua universidade, que estavam na Unidade Básica de Saúde (UBS), para realizar a intervenção na escola. Como você compreende essa situação? Justifique”.

${ }^{7}$ Questão no 21: "Durante uma intervenção sobre sexualidade com alguns estudantes de Medicina, enfatizando o tema da diversidade sexual, surge o seguinte comentário no grupo: 'Não entendo por que precisamos falar sobre isso, o preconceito não existe mais, tenho vários amigos gays'. Logo após, outro comentário é manifestado: 'Isso não me entra na cabeça, para mim o certo
} 
serem indagados "O que você compreende por sexualidade?".

\section{ANÁlise Dos QuESTIONÁRIOS: O REGISTRO DO INDICADOR “OPÇÃO SEXUAL"}

Iniciando as análises pelos questionários, a partir de questões que contemplavam as vivências dos sujeitos no curso e suas experiências em práticas pedagógicas questões que abordavam Situações da Vida Real -, registramos um indicador de categoria que ficou em evidência. Verificou-se o uso frequente das expressões "opção sexual" e "escolha sexual" por vários/as docentes, em vez de "orientação sexual". Vejamos alguns exemplos de respostas apresentadas ao longo dessas questões que envolviam temáticas da diversidade:

Abordar desde o início o tema sobre gênero, sexualidade e opção sexual. (Respondente $\mathrm{n}^{\circ} 10$ ) Já atendemos em UBS [Unidade Básica de Saúde] paciente com opção sexual diversa do sexo biológico, em uso de hormônios, também com opção de uso de nome que lhe for de desejo, tendo sido atendido em seus pleitos e criando relacionamento de toda serenidade. (Respondente $\mathrm{n}^{\circ} 12$ )

Incentivar o respeito pelas opções de cada indivíduo sobre a sua opção sexual, acolhendo-o e tratando-o em sua integralidade. (Respondente $\left.\mathrm{n}^{\circ} 14\right)$

Opção sexual deve ser respeitada. (Respondente $\left.\mathrm{n}^{\circ} 15\right)$

Especificamente durante a análise da questão $\mathrm{n}^{\circ}$ 21, que apresentava uma situação real ocorrida no curso durante uma conferência ${ }^{9}$ e solicitava aos docentes participantes um posicionamento justificado, tivemos como respostas, por exemplo:

Acho que cada um tem sua opinião, até porque temos que levar em consideração a educação (como foi criado, família), mas procuraria debater o assunto de forma ética; não importa a escolha sexual do paciente, e sim do doente. (Respondente $\mathrm{n}^{\circ}$ 9)

Explicaria sobre a diversidade de opções existentes. (Respondente $\mathrm{n}^{\circ} 10$ )

O livre arbítrio é prerrogativa pessoal; acredito que a discussão é o que esclarece as dúvidas, portanto, servir de base para possível reavaliação de 'fator estabelecido'. (Respondente $\mathrm{n}^{\circ} 17$ )

Conduziria os alunos no sentido de melhorar a compreensão dos mesmos acerca do assunto, tendo em vista que os comentários parecem vir

\footnotetext{
é homem e mulher e se eu tiver um paciente homossexual vou tratá-lo como doente porque para mim é o que ele é. Se sua ação pedagógica se defrontasse com os referidos comentários ou semelhantes, como você conduziria o diálogo com os/as estudantes? Porquê?".

${ }^{8}$ Questão no 22: "Pesquisa científica buscou conhecer o processo de transformação de sujeitos transgêneros, suas características e experiências. A partir de entrevistas realizadas, identificou-se que as travestis participantes relataram evitar procurar as UBS por preconceito. Relataram, também, fazer uso de hormônios sem nenhum acompanhamento médico, além de aplicarem silicone industrial em seus corpos como alternativa na busca de transformação pela aspiração ao feminino. Qual sua opinião sobre essa situação e como poderia orientar seus estudantes?".

${ }^{9} \mathrm{O}$ cenário "Conferência" ocorre do $1^{\mathrm{o}}$ ao $4^{\mathrm{o}}$ ano, uma vez por semana, e o/a palestrante pode ser um/a professor/a da própria universidade ou profissionais convidados.
} 
de um conhecimento baseado na vivência de cada estudante e não de um estudo aprofundado e confiável do tema. Importante ressaltar que é necessário respeitar a opinião que cada um vai formar após sedimentação do conhecimento. (Respondente $n^{\circ} 28$ )

Solicitando que cada participante expresse seu comentário. Todas as pessoas devem ser respeitadas. (Respondente $n^{\circ} 29$ )

Deve-se respeitar a opinião de cada um, mas orientar da necessidade de mais estudos e esclarecimentos adequados. (Respondente $n^{\circ} 33$ )

Ressaltamos que a expressão "a opinião deve ser respeitada" foi utilizada por vários/as docentes frente à situação apresentada, assim como "o médico não deve expressar sua opinião pessoal”. Vejamos mais alguns exemplos:

A preferência sexual não é determinante. (Respondente $\mathrm{n}^{\circ}$ )

Creio que colocaria justamente sobre as diversas percepções e experiências e da necessidade de ampliar o diálogo além de suas opiniões ou preconceitos. Simultaneamente, colocar em discussão sobre os aspectos da sociedade que estão presentes quando se fala de temas complexos como é o caso da sexualidade. (Respondente $\mathrm{n}^{\circ} 2$ )

Tentaria perguntar o porquê daquela situação. Que nós lidamos no dia a dia com questões de gênero e que precisamos estar capacitados para lidar com as diversas tipologias de gênero. (Respondente $\mathrm{n}^{\circ}$ 6)

Entendo que devam ser tratadas as patologias para o sexo masculino e/ou feminino. (Respondente $\mathrm{n}^{\circ} 8$ )
Observo que nos comentários há a negação e o preconceito. ... Os instigaria a levantar o assunto em ciclos de aprendizagem, mais diálogo, procura de outros profissionais, como pedagogos, sexólogos... porque somos iguais com diferentes orientações e todos deveremos ter consciência disto. (Respondente $\mathrm{n}^{\circ} 11$ )

Precisa-se orientar sobre as diferenças de cada um, sem preconceitos. (Respondente $n^{\circ} 18$ )

As falas reforçam a importância do assunto, uma vez que demonstram os vários posicionamentos e julgamentos sobre o assunto. Minha sugestão seria retomar o assunto, orientando os estudantes sobre a relevância do tema e todas as implicações biológicas e culturais que estão entremeadas. (Respondente no 25)

Orientaria que o médico não deve expressar sua opinião pessoal, mas sim orientá-lo do ponto de vista médico para prevenção e tratamento de doenças! Não cabe ao médico julgar, mas sim assistir. (Respondente $\mathrm{n}^{\circ} 26$ )

Iniciaria 0 trabalho discutindo sobre preconceito e inclusão ao tema sexualidade em um ciclo de aprendizagem. Discutiria (orientaria) a abordagem e o acolhimento de gêneros, na consulta médica. (Respondente $\mathrm{n}^{\circ} 30$ )

Confrontaria as duas falas e faria os estudantes refletirem sobre preconceito, aceitação, conhecimento sobre o tema, ética médica, entre outros. (Respondente no 34 )

Embora alguns docentes não tenham apresentado justificativa, de maneira geral, frente à situação apresentada, as respostas acima evidenciaram a importância de se resgatar o debate com os/as estudantes, ampliar a discussão sobre o tema, inclusive com o auxílio de outros profissionais especialistas. 
São atitudes que parecem apontar uma possível superação do paradigma cartesiano de ensino - a educação bancária denunciada por Paulo Freire -, uma vez que indicam a busca de uma educação dialógica e problematizadora, como proposta nos marcos teóricos do Projeto Pedagógico do Curso (PPC), que visem ao diálogo, à humanização e à possível mudança do comportamento humano, visto que muitas respostas acima enfatizaram a importância de respeitar as diversidades, não julgar os pacientes e não ter preconceitos.

Ao caminhar numa perspectiva paradigmática que promova o entendimento do ser humano em sua inteireza, a compreensão da diversidade sexual é indissociável da compreensão da sexualidade como um direito humano. A Declaração dos Direitos Sexuais (WAS, 2014) reconhece que "a orientação sexual, identidade de gênero, expressões de gênero e características físicas de cada indivíduo requerem a proteção dos direitos humanos", não se tratando, assim, de uma "opinião pessoal” (p. 3). Esse entendimento começa a ser demonstrado em algumas respostas referentes à questão $n^{\circ} 21$, como, por exemplo:

Que devemos respeitar as diversidades e, mais do que isso, promover saúde. Não devemos julgar os pacientes, apenas tratá-los e promover a saúde e a felicidade de cada um. Seria interessante promover um debate/ciclo/tutoria com um embasamento científico nos estudos sobre homossexualidade. Incentivaria a busca por informações e os fatos ajudariam o estudante a mudar de opinião. Mesmo que não mude, pelo menos veria o quanto errado poderia estar, e que sua rebeldia não agregaria em nada ao estado de saúde do seu paciente. (Respondente $n^{\circ} 5$ )

Há informação literária suficiente para criar uma discussão construtiva sobre o assunto. Tanto do ponto de vista psicológico quanto social.
Fomentaria a discussão em grupos após o devido embasamento teórico. (Respondente $\mathrm{n}^{\circ} 27$ )

As respostas acima chamam a atenção para um importante ponto: o aspecto científico do campo da sexualidade, que muitas vezes é banalizado. Figueiró (2006) já apresentava, na primeira década dos anos 2000 , a preocupação de que existam intervenções em sexualidade ainda fundamentadas no senso comum, ou seja, intervenções realizadas sem o necessário preparo, ressaltando a necessidade de constante estudo, ressignificação de si, dos outros e de sua visão de mundo - um processo denominado de "reeducação sexual". Muitos de nós, profissionais da Educação e da Saúde, de acordo com Santos e Bruns (2000), podemos ser "frutos" de uma "má" formação em sexualidade, uma vez que, muito provavelmente, nossa formação inicial não se fundamentou em um paradigma emancipatório, com intervenções críticas em sexualidade voltadas à emancipação de sujeitos, mas ao seu controle e à sua repressão, por meio da reprodução inconsciente e acrítica de mitos, tabus, crenças e pré-conceitos estabelecidos e naturalizados hegemonicamente em sociedade.

Nesse sentido, as respostas acima sugerem que os debates e/ou discussões sobre essa temática, quando ocorrem, ainda podem estar norteados pelo senso comum. Isso aponta para a importância da busca pela produção de conhecimento científico amplamente produzido na área da sexualidade humana seja na forma de dissertações, teses, livros e/ou publicações em periódicos. E esse movimento pode ser registrado em mais algumas respostas, como:

Esta oportunidade é importante para problematização do tema. Como ação pedagógica, estimularia a busca bibliográfica sobre a temática para futura discussão do tema. (Respondente $\mathrm{n}^{\circ} 4$ ) 
Os comentários citados são muito frequentes. Ambos não dão conta da maioria das situações enfrentadas a respeito. A melhor forma, acredito, ainda é o diálogo informado. As discussões sobre o tema, no momento em que ele surge - da prática -, devem partir dos conhecimentos e vivências dos próprios estudantes, com as diferentes visões, e, a partir daí, buscar - através de mais informações e conhecimento -, aprofundar o tema e discutir a melhor maneira de trabalhar as situações experienciadas. (Respondente $n^{\circ} 14$ )

O ideal é problematizar e buscar conteúdo bibliográfico para discussão. (Respondente $\mathrm{n}^{\circ}$ 19)

Proporia uma análise reflexiva, talvez com auxílio de textos e/ou vídeos. (Respondente $\mathrm{n}^{\circ}$ 23)

Primeiro, oferecendo espaço para que eles aprofundem conhecimentos (teóricos) sobre sexualidade e gênero (os diversos tipos), e depois problematizaria com eles. (Respondente $n^{\circ} 31$ )

Em síntese, as respostas às questões que abordavam Situações da Vida Real e, especificamente, à questão $n^{\circ} 21$ também ressaltaram o dever de respeitar as diversidades, de promover saúde e inclusão, de combater o preconceito, de incentivar o embasamento científico, assim como a importância do diálogo informado e da atitude ética. Consequentemente, encontramos nas respostas, ainda, resquícios do não entendimento da orientação sexual como um direito e uma dimensão inseparável do humano, não se tratando, portanto, de uma “questão de opinião". Ainda não há uma noção da orientação sexual como um direito humano, visto que apenas uma resposta enfatizou a orientação sexual como um aspecto de direito dos sujeitos: "Focar o sujeito que tem direito sobre sua aptidão sexual e merece, no mínimo, respeito" (Respondente no 22 ).

Há que ressaltar a importância, na fala citada, do reconhecimento do direito à diversidade de orientação sexual. E, inclusive, destacamos surpreendentemente que em apenas uma única resposta foi afirmado que a homossexualidade não é uma doença. Tal aponta para a urgente e necessária reflexão crítica e racional que amplie a compreensão sobre a orientação sexual e as diversidades:

A abordagem deveria ser problematizada, sendo recomendado estudo sobre o tema, e seria recomendado literatura pertinente, evidente, o enfoque seria abrangente, aberto, aceitação da opção sexual de cada indivíduo, sem preconceitos; também se poderia recomendar CID - 10, e recomendações já definidas de não ser doença a opção sexual, respeitando amplas percepções, definição sexual cabe a cada ser. Textos sobre médicos com opção sexual diversa do habitual. (Respondente $n^{\circ} 12$ - questão no 21 )

Como afirma a resposta acima, embora também utilizando a expressão "opção sexual", relembramos, notadamente, que em 1985 o Conselho Federal de Medicina brasileiro apresentou recomendações de que a homossexualidade não fosse mais codificada pelo item 302.0 do Código Internacional de Doenças (CID) - que catalogava o "homossexualismo" como "Desvios e Transtornos Sexuais" -, mas no item V62 "Outras Circunstâncias Psicossociais"10. E em 1990 a OMS retirou o termo do código, sendo que o Manual de Diagnóstico e Estatística dos Transtornos Mentais (DSM-V) também retirou o termo de suas classificações, visto não

\footnotetext{
${ }^{10}$ Recuperado em 04/04/2018 de http://www.portalmedico.org.br/pareceres/cfm/1985/5 1985.htm
} 
se tratar de uma doença e, menos ainda, uma doença mental - e o termo "homossexualismo" foi abolido. Em um colegiado de um Curso de Graduação em Medicina - e que, portanto, formam futuros médicos e médicas - esse dado concreto não pode ser ignorado, pois são mudanças que foram desencadeadas há mais de 30 anos.

Recordamos que o termo "homossexual" foi criado no século XIX pelo austro-húngaro Karl-Maria Benkert ${ }^{11}$ (1824-1882), jornalista, tradutor, escritor e defensor dos Direitos Humanos. Além de lutar pelos direitos das pessoas homossexuais, Benkert também criou os termos "heterossexual" e "monossexual" referente à masturbação, seja homem ou mulher (Vieira, 2009). Segundo Guimarães (2009), o termo homossexual foi criado no ano de 1869. De acordo com as fontes citadas, ao criar os termos, principalmente o de homossexual, Benkert não lhes atribuiu conotações negativas. Logo, não lhes conferiu um entendimento de desviante ou de anormalidade - como hoje, muitas vezes, ainda são considerados por parte da população em geral.

Contudo, nessa mesma época, os "psiquiatras começaram a desempenhar um papel fundamental na construção oficial de uma teoria da normalidade e anormalidade sexual" (Vieira, 2009, p. 492). Nesse sentido, a Medicina cria classificações de "normalidade" e "anormalidade" e, especificamente, ainda segundo Vieira (2009), o psiquiatra e sexólogo alemão Richard von Krafft-Ebing apropria-se do termo e oficialmente utiliza-o na $4^{\text {a }}$ edição de sua obra Psychopathia Sexualis, de 1889, que estudava comportamentos e desvios sexuais.

Assim, o termo homossexualismo foi "criado no final do século XIX por médicos" (Bortolini, 2008, p. 9), sendo "rapidamente vinculado a uma doença que deveria ser tratada" (Guimarães, 2009, p. 559). Deste modo, a Medicina, firmada pelo discurso clínico, detém um "domínio epistemológico" sobre os sujeitos e, por meio da concepção higienista, promove a normalização de condutas aceitáveis e não aceitáveis sobre a vida íntima dos sujeitos (Foucault, 2008). Condutas classificadas perante o poder, a regulação do discurso clínico, e caracterizadas como "normal" e "anormal" acabaram por patologizar a diversidade e a diversidade sexual, bem como suas práticas e vivências. Silva (1998) também ancorou sua pesquisa nas considerações de Foucault a respeito da ciência como um artifício de poder, visto que relaciona o saber médico em sexualidade com o poder de classificar e enquadrar padrões de normalidade e anormalidade. Machado (1978), na década dos anos 70, já sinalizava para este domínio e enquadramento, o que reforça o controle sobre os sujeitos: "A medicina... deve guiar o processo de estabelecimento e o funcionamento desta sociedade, apontando sempre as causas de alterações e nelas intervindo" (p. 197).

A medicina clínica, então, pode ser caracterizada tanto como um "conjunto de prescrições políticas, decisões econômicas, regulamentos institucionais, modelos de ensino, quanto um conjunto de descrições" (Foucault, 2008, p. 100). Destarte, como esclarece Vieira (2009), a homossexualidade, “ao invés de ser descrita enquanto uma variante da sexualidade, como, originalmente, pretendia Kertbeny, tornou-se, nas mãos de sexólogos pioneiros tais como Krafft-Ebing,

\footnotetext{
${ }^{11}$ Karl-Maria Benkert (nome original) nasceu em Viena, na Áustria. Mais tarde, sua família mudou-se para Budapeste, capital da Hungria, e seu nome foi modificado para Károly Mária Kertbeny (nome húngaro). Adiante, Benkert mudou-se para Berlim e se radicou na Alemanha, onde se chamou Karl-Maria Kertbeny (nome alemão). Recuperado em 29/09/2017 de http://karl-mariaketbeny.blogspot.com.br
} 
uma descrição médico-moral" (p. 493). Consequentemente, como afirma Bortolini (2008), o termo homossexualismo "carrega uma ideia conservadora que enxerga os homossexuais como doentes ou desviantes" (p. 9). Davi (2013) também se fundamenta em Foucault e questiona esta "forma normatizante" adotada tanto por saberes médicos como jurídicos:

Homossexuais, principalmente aqueles mais afeminados, foram encarados como doentes e a partir daí vigiados e perseguidos por médicos, psiquiatras e pela polícia dos costumes. No imaginário social da primeira metade do século XX, a efeminação, o travestismo e o homossexualismo caracterizavam patologias que careciam de tratamento como ingestão de hormônios masculinos, exercícios físicos, medicamentos, dentre outros. (p. 38)

Nesse sentido, o sufixo "ismo", associado à palavra homossexual, reforçou

na representação da palavra os pressupostos da época (religioso-moralista, médico-patológico, jurídico-criminal) para os relacionamentos entre pessoas do mesmo sexo, ou seja, algo de natureza anormal, essencialmente patológico, doente, desviante, perverso, pecaminoso. (Furlani, 2003, p. 153)

E, ao ser substituído pelo sufixo "dade", promoveu um ressignificado, trouxe "um sentido de expressão, manifestação humana (identidade, felicidade, espontaneidade, sexualidade)" (Bortolini, 2008, p. 9).
Destacamos, inclusive, que o Conselho Federal de Psicologia (CFP) brasileiro proibiu em 1999 - Resolução no 001/99, de 22 de março de $1999^{12}$ - todos os seus profissionais de oferecerem ou realizarem tratamento que vise à "cura" da homossexualidade, visto que não é uma doença. Contraditoriamente, esse assunto volta à tona no Brasil em pleno ano de 2017 do século XXI numa ação popular ${ }^{13}$ movida por um grupo de psicólogos/as que defendem o uso de terapias de reversão sexual, fundamentados em princípios religiosos ao invés de embasamento científico. Atualmente, o CFP interpôs agravo de instrumento contra a liminar relacionada à Resolução n 001/99, devido ao seu caráter paradoxal, "porque, ao mesmo tempo, mantém o texto da resolução, mas a descaracteriza ao reconhecer a (re) orientação sexual como possibilidade de intervenção dos psicólogos" ${ }^{\prime 14}$.

Curiosamente, em uma das respostas nos questionários, referente à questão $\mathrm{n}^{\circ} 21, \mathrm{o} / \mathrm{a}$ participante ressaltou: "Acho que devemos tratar a sexualidade como um assunto normal; quanto mais se valoriza o tema, mais conflitos gera" (Respondente no 9). Mas, diante de todo o exposto, que, além de representar uma violação grave de direitos humanos em um país que está no ranking mundial de crimes motivados pela homo/transfobia à comunidade LGBT, aponta-nos para uma possível (de)formação profissional/inicial/continuada/permanente - tanto de profissionais da Educação como da Saúde, por não refletirem consciente $\mathrm{e}$ criticamente esta temática -, questionamonos: devemos evitar os conflitos?

Ainda, alguns docentes também relataram

\footnotetext{
12 Recuperado em 29/09/2017 de http://site.cfp.org.br/wp-content/uploads/1999/03/resolucao1999 1.pdf

${ }^{13}$ Ata de audiência recuperada em 30/10/2017 de http://site.cfp.org.br/wp-content/uploads/2017/09/Decis\%C3\%A3o-LiminarRES.-011.99-CFP.pdf

${ }^{14}$ Recuperado em 30/10/2017 de http://site.cfp.org.br/conselho-federal-de-psicologia-interpoe-agravo-de-instrumento-contra$\underline{\text { liminar-relacionada-resolucao-0199/ }}$
} 
que apresentam dificuldade para trabalhar a diversidade e outros aspectos da sexualidade, sendo que muitos explicitaram a necessidade de orientação sobre o assunto. Esse entendimento pode ser observado nas respostas apresentadas anteriormente, mas também em outras diferentes respostas que percorreram todo o questionário, e especificamente na questão $\mathrm{n}^{\circ}$ $25^{15}$. Vejamos alguns exemplos:

Acho o tema sexualidade importante nos dias atuais devido ao grande número de homossexuais que atendemos e às dificuldades que nós, profissionais e estudantes, encontramos. (Respondente no 9 - questão n²5)

Ainda ficamos muito no biológico. Tenho dificuldades também em abordar tal assunto com os estudantes. Devemos nos capacitar, estudar também... e muito. (Respondente $\mathrm{n}^{\circ} 11$ - questão $\mathrm{n}^{\circ} 21$ )

Tive aluno(a) transexual e tive dificuldades para lidar com o assunto. Preciso de orientação para depois orientar alunos. (Respondente no 24 - questão no 22)

Sinto enorme dificuldade em lidar com situações que envolvem esta temática porque minha formação acadêmica e minha vivência profissional não me instrumentalizaram para conduzir algumas situações e não tenho conhecimento adequado sobre $\mathrm{o}$ assunto. (Respondente $n^{\circ} 25$ - questão n²5)

Precisamos, enquanto profissionais de saúde, docentes e cidadãos, compreender mais sobre este tema da atual sociedade de modo que saibamos agir com ética e respeito à diversidade. (Respondente $n^{\circ} 31$ - questão no 25)

Inclusive, quando questionados sobre suas vivências em formações continuadas ${ }^{16}$, dentre os/as 34 respondentes apenas sete afirmaram que já participaram de alguma formação (a maioria palestras). E, posteriormente, quando questionados sobre a importância de formações nessa temática ${ }^{17}, 31$ docentes responderam que consideram muito importante.

Assim, no que se refere à (de)formação profissional e docente, algumas respostas apresentadas podem ser reflexo da ausência de espaços intencionais para se trabalhar o tema numa perspectiva emancipatória $e$ crítica, pois as respostas sugerem a vivência de um processo de formação profissional onde a compreensão da dimensão sexualidade, muitas vezes, se perpetua num viés repressor e por meio do currículo oculto e, ainda, nos casos dos formados na área médica, também essa ausência de formação específica pode ser fruto de cursos ancorados no paradigma da medicina científica. Em ambos os casos, resultando numa expropriação da consciência positiva dessa dimensão humana, pois, na maioria das vezes, vinculados a abordagens ancoradas no discurso "biológico científico", reproduzem um viés tecnicista, reducionista e fragmentado do humano, em suas práticas profissionais.

\footnotetext{
${ }^{15}$ Questão no 25: "Aproveite o espaço abaixo para deixar sua contribuição para esta pesquisa”.

${ }^{16}$ Questão no 23: "Você já participou de alguma formação continuada (mini curso, curso de extensão, etc.) sobre sexualidade e/ou educação sexual? Se sim, quando e em qual instituição?".

${ }^{17}$ Questão no 24: "Considera importante a universidade oferecer formação sobre este tema aos docentes? Se sim, como acredita que deveria ser? Se não, justifique o porquê".
} 
4. ANÁlise DAS ENTREVISTAS: A REAFIRMAÇÃO DO INDICADOR “OPÇÃO SEXUAL” E A IMPORTÂNCIA DA FORMAÇÃO DOCENTE

Destacamos, primeiramente, que a coleta de dados realizou-se durante um momento tensional no curso. Conforme relatos da altura, a presença de um estudante transexual gerou muitas inquietações, conflitos e dúvidas, especialmente no ambiente hospitalar. $\mathrm{O}$ uso de banheiro/vestiário no hospital foi relatado por vários/as docentes como o argumento cerne das discussões. Frente à situação, em julho de 2015, anteriormente ao início da coleta de dados, a coordenação do curso organizou uma formação continuada e ofertou ao colegiado uma palestra sobre Sexualidade e Gênero. Apenas uma pequena parcela do colegiado esteve presente, mas a intervenção foi positiva e de grande contribuição.

Nas falas dos/as participantes, como já visto nos questionários, registramos o uso constante da palavra "opção sexual" por vários docentes, além de termos, como, por exemplo, "escolha sexual" ou "optando sexualmente", por outros/ as. Reiteramos que a palavra "opção" apontanos que os sujeitos parecem escolher a maneira de sentir/vivenciar seus desejos. A maioria de nós, profissionais da Educação e da Saúde, tem muitas marcas da vertente médico-biologista somada ao paradigma da medicina científica, o que reforça um padrão heteronormativo e um entendimento que contradiz a sexualidade como inerente ao humano e plural. Neste sentido, como podemos falar em escolha? Se somos todos e todas seres sexuados, inclusive no viver adulto dos desejos sexuais, a orientação sexual é parte do existir humano; portanto, não é uma opção.

Isso evidencia um equívoco, talvez insegurança, em acolher e trabalhar o tema por não termos clareza de que somos todos e todas sempre sexuados, erotizados e sensualizados, inclusive no que diz respeito aos Direitos Sexuais (WAS, 2014) enquanto Direitos Humanos universais e fundamentais. Assim, usar o termo "opção" aponta para o entendimento de que precisamos avançar, pois, mesmo que inconscientemente, expressa a não compreensão da diversidade como riqueza humana, incluído, portanto, o não entendimento de que as diversas maneiras de amar são diferentes vivências do humano em plenitude em sua orientação sexual.

Assim, o indicador de categoria "opção sexual” está presente, de forma geral, por toda a fala daqueles que a utilizam e o apresentaremos aqui associado a algumas respostas sobre compreensão de sexualidade dos/das docentes, quando questionados/as: "O que você compreende por sexualidade?". Vejamos alguns exemplos:

... a primeira coisa que vem é a opção sexual, né? Com quem você se relaciona. Embora, assim... num conceito muito mais amplo é... também vai do... tipo... do que a pessoa se identifica, né?, como que ela se identifica ou como que ela se insere num meio, né?... É... (silêncio)... Mas acho que assim, a questão-chave... a primeira coisa que vem na minha cabeça é com quais pessoas você se relaciona. Mas... eu sei que não é tão simples assim. Mas basicamente... o que me vem na cabeça, basicamente, é isso. (Hades, Med.)

Sexualidade? Bom... ah... (pausa). Quando você pergunta em relação a... quando a gente fala de sexualidade, né? A opção sexual? Sexualidade... (pensativa)... é que são diversos conceitos, né? Opção sexual, sexualidade... daí tem a sensualidade... daí têm... as questões das relações sexuais, né?... da opção da escolha do gênero, do... (pausa mais longa). O que que eu entendo? Nunca parei pra refletir. (Áceso, Não med.) 
É... opção sexual... é... coisas relacionadas a sexo... é o que vem na minha cabeça. Só que eu acho que a sexualidade ainda é vista com mais tabu, com mais preconceito do que qualquer outra coisa. Porque é cultural, a gente foi criado assim... foi colocado um monte de coisa na cabeça da gente desde que a gente é criança. (Aglaea, Med.)

Por meio das falas apresentadas, e nas análises dos dados da pesquisa em sua totalidade, os relatos apontam que a compreensão da dimensão sexualidade está diretamente relacionada à compreensão da diversidade e às formas de vivência dos desejos. Como refletido anteriormente, é a atenção voltada para o diverso, mas como algo que sai do padrão dito "normal" ou que não corresponde às nossas práticas e ações, entendidas como as únicas possíveis. Essa é uma herança dos paradigmas repressivos e reducionistas da dimensão sexualidade, que fragmenta nosso olhar e estabelece à Medicina um papel de identificar o estranho, o que sai da norma, o "anormal", com vistas a reconduzir esses sujeitos à vivência sadia e "normal" da sexualidade.

Ainda, Aglaea, em seu processo de antítese, ressalta que a dificuldade de se discorrer sobre o assunto pode ser cultural, pois identifica que desde a infância já se adotam comportamentos repressivos e/ou omissos, propagando tabus e preconceitos. Vejamos mais exemplos:

Pegando esse assunto específico da... da escolha, né?... sexual de cada um. E... eu vejo que... isso não tem assim grandes problemas pra nós enquanto tratar com o outro. (Afrodite, Não med.)

E este ano... assim a gente viu... inclusive na Medicina... vários se decidindo sexualmente, né?... optando sexualmente. (Hygeia, Não med.)
O indicador de categoria "opção sexual" representa a negação de um processo de educação sexual emancipatório. Entender a orientação sexual como opção ou escolha indica uma abordagem reducionista e equivocada com reflexos importantes nas ações de profissionais da área da Saúde. Ressaltamos que um dos pontos que almejamos, a partir de um processo de educação sexual emancipatória, é o aceite respeitoso da diversidade, da diferença, do outro e das diferentes maneiras de amar. Compreendemos, nesse sentido, que, ao falar em "opção sexual", entende-se implícita a noção da diversidade, mas ainda transitando como uma questão individual. Registramos, também, o uso da palavra "homossexualismo", como podemos verificar:

Nas aulas, às vezes, que a gente tinha de ética e de... como é que era o nome daquela?... Não era só ética... Uma outra cadeira, que era um psiquiatra que dava, a gente discutia essas questões. Aborto, gravidez na adolescência... e aí acabava, às vezes, discutindo homossexualismo. (Láquesis, Med.)

Tem que fazer! Tu não viu que outro dia chamaram... daí começou a surgir a situação de sexualidade... de homossexualismo... de não sei o quê... Estavam todos os professores apavorados. (Deméter, Med.)

Enquanto Láquesis comenta sobre como foi sua vivência na formação profissional, Deméter reforça a necessidade de formação continuada com o corpo docente. Recordamos que a palavra "homossexualismo" se fez presente também nas respostas dos questionários. Como discorrido, o termo remete a pessoas homossexuais, incluída também a comunidade LGBT, como doentes ou desviantes, representando, assim, o reflexo de paradigmas repressores, reducionistas e patologizantes ainda em vivência nos nossos pensamentos 
e ações, inconsciente e acriticamente. Ainda, uma possível confusão entre os termos "orientação sexual" e "identidade de gênero" também pode ser apontada durante as análises, por outra docente. Como, por exemplo: “Eu tive um... eu fui professora da... você deve ter sabido [sobre estudante transexual], que hoje fez a opção sexual, né?..." (Aglaea, Med.).

Cabe lembrar que orientação sexual diz respeito ao foco dos desejos dos sujeitos, e identidade de gênero ao gênero ao qual a pessoa se identifica. E essa compreensão, em nosso entendimento, importante e obrigatória, deve ser refletida criticamente em cursos de formação continuada e permanente, tanto no colegiado em questão como em todos os cursos da área da Educação e Saúde, especialmente os que formam futuros médicos e médicas. Sabemos da importância social de professores e professoras, tanto da área da Educação como da Saúde, e das suas contribuições especialmente da contribuição do profissional da área médica - que podem vir a dar vida a processos intencionais emancipatórios de educação sexual, no desenvolvimento de projetos embasados numa nova ética em torno da dimensão humana da sexualidade. É verossímil a responsabilidade e autoridade destes profissionais enquanto formadores de opinião ao trabalharem esta temática, seja como convidados nos ambientes escolares, nos próprios cursos de Medicina e/ou na prática profissional.

Por fim, destacamos que o questionário foi extremamente válido para fazer um levantamento diagnóstico do perfil dos respondentes e de suas compreensões diante de situações-problema reais apresentadas. A entrevista possibilitou a oportunidade de fala aos participantes voluntariados e, consequentemente, o aprofundamento das informações, expressadas com mais riqueza de detalhes. Logo, destacamos que a orientação sexual não foi apenas nomeada equivocadamente ao expressarem suas opiniões sobre a temática. Pelo método dialético, buscamos a essência e não a aparência do fenômeno em estudo, visto que as compreensões não se mostram explicitamente. Assim, fundamentadas no materialismo histórico dialético como paradigma de visão de mundo, compreendemos que nenhum comentário é neutro ou não-intencional; portanto, não se trata apenas de um simples equívoco.

\section{Considerações Finais: Nossas} VERDADES PROVISÓRIAS

A partir das análises, em sua totalidade, as contradições identificadas representam, no método dialético, que o processo está vivo e em movimento, ou seja, não estático. A contradição é a essência da dialética e entendida, não como um aspecto negativo na prática docente, mas como sinal de esperança. É sinal de que este curso de Medicina está vivo, dinâmico, em transformação, em transição, e, consequentemente, o que-fazer docente também. Por isso, a contradição representa um processo de saúde pedagógica no curso, pois a ausência de contradições revelar-nos-ia um curso cristalizado e determinado, paralisado numa verdade sem movimento.

Este estudo reforça a importância de se problematizar intencionalmente a temática da sexualidade humana em um viés emancipatório em cursos de formação médica, inclusive em currículos inovadores, que promovam mudanças paradigmáticas curriculares. As análises registraram que, efetivamente, a reprodução do termo "opção sexual" é acrítica e inconsciente. Mesmo após décadas em que a homossexualidade não é mais classificada como doença, muito menos como doença mental, ainda ocorre sua reprodução no senso 
comum, tanto na escrita (questionários) como na fala (entrevistas), o que aponta, pelo método dialético, para indícios de alienação. Consequentemente, a orientação sexual e a vivência dos sujeitos fora dos padrões heteronormativos ainda não está sendo compreendida como um aspecto saudável e de direito.

Diante do exposto e do fato de que uma estrutura curricular inovadora isoladamente pode não promover reflexão crítica e ressignificação dos sujeitos no campo da sexualidade, torna-se urgente e necessário o fortalecimento da formação continuada e permanente dos/as docentes. Para se fortalecer vivências emancipatórias e o respeito às diversidades, deve se promover um processo de reeducação sexual e se debater, intencional, consciente e criticamente, temáticas da sexualidade humana, com vistas à superação do senso comum. Em pleno século XXI, quando vivemos no Brasil perdas de direitos humanos e retrocessos sociais, é imprescindível que profissionais da Educação e da Saúde, especialmente médicos e médicas, reflitam criticamente sobre sexualidade, gênero e educação sexual.

Os/as docentes caminham em suas vivências pedagógicas influenciados concomitantemente por dois paradigmas: o velho olhar, que representa uma formação tradicional, cartesiana, tecnicista, fundamentado pelo paradigma da medicina científica em interface com a vertente médico-biológica; e o novo olhar, que representa uma educação problematizadora, centrada no estudante, que almeja a formação de profissionais médicos críticos, humanos, cidadãos e autônomos, significando neste contexto, portanto, uma mudança paradigmática almejada em andamento. E suas compreensões do processo de educação sexual vivido refletem isso. Os/ as docentes participantes, em sua maioria, apresentam enorme comprometimento com o curso e todos/as, com beleza e humildade, confiaram-nos suas fraquezas e suas fortalezas. Enfrentam corajosamente o processo de expropriação, vivido por todos nós, em relação à sexualidade, na busca da potencialização da compreensão do humano na sua inteireza portanto, sempre sexuado.

Num entendimento dialético da realidade, a dimensão sexualidade está sempre em movimento, em transformação, e é inseparável do existir humano. Por isso, um processo de reeducação sexual torna-se imprescindível na busca da consciência crítica e racional dos sujeitos sobre si, sobre o outro e sobre o mundo. Assim, as contradições representam o inacabamento humano, o movimento dialético que aponta estarmos sempre em transformação, em busca de uma mudança paradigmática, em busca da vivência do PPC em plenitude - onde há, sim, possibilidades de se vivenciar um processo de educação sexual emancipatório.

\section{REFERÊ NCIAS}

Bardin, L. (2014). Análise de conteúdo (4ª ed.) Lisboa: Edições 70.

Bortolini, A. (2008). Diversidade sexual na escola ( $1^{\text {a }}$ ed.). Rio de Janeiro: Pró-Reitoria de Extensão/UFRJ.

Brasil. (2001). Conselho Nacional de Educação. Câmara de Educação Superior. Diretrizes curriculares nacionais do curso de graduação em Medicina. Resolução $\mathrm{n}^{\circ}$ 4, de 07/11/2001. Diário Oficial da União, 09/11/2001, Brasília, Seção 1, p. 38.

Brasil. (2014). Conselho Nacional de Educação. Câmara de Educação Superior. Diretrizes curriculares nacionais do curso de graduação em Medicina. Resolução $\mathrm{n}^{\circ}$ 3, de 20/06/2014. Diário Oficial da União, 23/06/2014, Brasília, Seção 1, pp. 8-11.

Cabral, J. T. (1995). A sexualidade no mundo 
ocidental. Campinas: Papirus.

Cardoso, F. L. (2008). O conceito de orientação sexual na encruzilhada entre sexo, gênero e motricidade. Revista Interamericana de Psicologial Interamerican Journal of Psychology, 42(1), 69-79.

Carvalho, G. M. D., Mendes, P. O. S. P., Melo, S. M. M., \& Santos, V. M. M. (2012). Educação sexual: Interfaces curriculares. Caderno pedagógico. Florianópolis: UDESC/CEAD/ UAB.

Davi, E. H. D. (2013). Belíssima: Um estudo merleau-pontyano da corporalidade travesti (Tese de doutorado). Universidade de São Paulo, São Paulo, Brasil.

Figueiredo, C. D. S. (2015). Adolescentes na sociedade do espetáculo e o sexting: Relações perigosas? Um estudo exploratório na busca de subsídios para programas de prevenção (Dissertação de Mestrado). Universidade do Estado de Santa Catarina, Florianópolis, Santa Catarina, Brasil.

Figueiró, M. N. D. (2006). Formação de educadores sexuais: Adiar não é mais possível. Campinas, SP: Mercado das Letras; Londrina, PR: Eduel.

Foucault, M. (2008). Arqueologia das ciências e história dos sistemas de pensamento ( $2^{\mathrm{a}} \mathrm{ed}$.) Rio de Janeiro: Forense Universitária.

Freire, P. (2005). Pedagogia do oprimido (29a ed.) Rio de Janeiro: Paz e Terra.

Freitas, M. (2016). Educação sexual em debate nas ondas da rádio UDESC FM 100.1 Florianópolis: Estudo de caso dos programas gravados de 2007 a 2015 (Dissertação de Mestrado). Universidade do Estado de Santa Catarina, Florianópolis, Santa Catarina, Brasil.

Furlani, J. (2003). Mitos e tabus da sexualidade humana: Subsídios ao trabalho em educação sexual ( $2^{\text {a }}$ ed.). Belo Horizonte: Autêntica.

Guimarães, A. F. P. (2009). O desafio histórico de "tornar-se um homem homossexual": Um exercício de construção de identidades. Temas em Psicologia, 17(2), 553-567.
Louro, G. L. (Org.). (2007). O corpo educado: Pedagogias da sexualidade (2a ed.). Belo Horizonte: Autêntica.

Machado, R. (1978). (Da)nação da norma: A medicina social e constituição da psiquiatria no Brasil. Rio de Janeiro: Edições Graal.

Melo, S. M. M., \& Pocovi, R. M. S. (2008). Educação e sexualidade (2a ed.). Florianópolis: UDESC.

Melo, S. M. M., Pocovi, R. M. S., Carvalho, G. D., Mendes, P. O. S. P., \& Santos, V. M. M. (2011). Educação e sexualidade (2a ed.). Florianópolis: UDESC/CEAD/UAB.

Moraes, R. (2003). Uma tempestade de luz: A compreensão possibilitada pela análise textual discursiva. Ciência \& Educação, 9(2), 191-211.

Netto, J. P. (2016). Introdução ao método de Marx. Palestra proferida ao Programa de Pós-Graduação em Política Social (PPGPS) da Universidade de Brasília/UNB em 19/04/2016. Recuperado de https://www. youtube.com/watch? $\mathrm{v}=2 \mathrm{WndNoqRiq} 8$

Nunes, C. A. (1996). Filosofia, sexualidade e educação: As relações entre os pressupostos ético-sociais e histórico-culturais presentes nas abordagens institucionais sobre a educação sexual escolar (Tese de Doutorado). Universidade Estadual de Campinas, Campinas, São Paulo, Brasil.

Nunes, C. A. (2005). Desvendando a sexualidade (7 a ed.). Campinas, SP: Papirus.

Oliveira, L. S. (2007). Representação de sexualidade que orienta práticas educativas no Brasil desde o final do século XIX (Dissertação de Mestrado). Universidade Estácio de Sá, Rio de Janeiro, Brasil.

Santos, C., \& Bruns, M. A. T. (2000). A educação sexual pede espaço: Novos horizontes para a práxis pedagógica. São Paulo: Ômega Editora.

Silva, E. (1997). Medicina e sexualidade humana: Estudo crítico do currículo atual dos cursos de Medicina e suas implicações na formação do médico (Dissertação de 
Mestrado). Pontifícia Universidade Católica, Campinas, São Paulo, Brasil.

Silva, E. (1998). A escola, a clínica e a sexualidade humana. Revista Perspectiva, 16(30), 115-142.

Stake, R. E. (2012). A arte da investigação com estudos de caso ( $3^{\mathrm{a}}$ ed.). Lisboa: Fundação Calouste Gulbenkian.

Triviños, A. N. S. (2012). Introdução à pesquisa em ciências sociais: A pesquisa qualitativa em educação. São Paulo: Atlas.

Vieira, L. L. F. (2009). As múltiplas faces da homossexualidade na obra freudiana. Revista Mal-Estar e Subjetividade, IX(2), 487-525.

Vieira, R. M., \& Vieira, C. (2005). Estratégias de ensino/aprendizagem: O questionamento promotor do pensamento crítico. Instituto Piaget: Lisboa.

World Association for Sexual Health. (2014). Declaração dos direitos sexuais. Recuperado de http://www.worldsexology.org/wpcontent/uploads/2013/08/DSR-Portugese. pdf

Yared, Y. B. (2011). Educação sexual na escola: Tensões e prazeres na prática pedagógica de professores de Ciências e Biologia (Dissertação de Mestrado). Universidade do Planalto Catarinense, Lages, Santa Catarina, Brasil.

Yared, Y. B. (2016). Do prescrito ao vivido: $A$ compreensão de docentes sobre o processo de educação sexual em uma experiência de currículo integrado de um curso de Medicina (Tese de Doutorado). Universidade do Estado de Santa Catarina, Florianópolis, Santa Catarina, Brasil.

Yared, Y. B., Melo, S. M. M., \& Vieira, R. M. (2015). Relevância do pensamento crítico para a educação sexual intencional emancipatória. In C. Dominguez (Coord.), Pensamento crítico na educação: Desafios atuais (pp. 233-239). Vila Real: UTAD. Disponível em https://repositorio.utad.pt/ bitstream/10348/4818/3/Pensamento $\% 20$ Crítico\%20na\%20Educação\%20-\%20

\section{Desafios\%20Atuais\%20\%5B2015\%5D.pdf}

$\begin{array}{lr}\text { SEXUAL OPTION } & \text { OR SEXUAL } \\ \text { ORIENTATION? } & \text { TEACHERS } \\ \text { UNDERSTANDINGS OF SEXUALITY IN A } \\ \text { MEDICAL DEGREE }\end{array}$

\section{Abstract}

This article presents part of the results of a research that investigated the perceptions of teachers of a medical degree programme on the human dimension of sexuality so that processes of sexual education, which were presented in a proposal of an innovative curriculum, could be unveiled. The research was guided by the dialectical historical materialism paradigm that uses the dialectical method to analyse reality. Questionnaires and interviews were the instruments for data collection. Content analysis revealed contradictions in the pedagogical practice that represents experiences anchored in the medical-biological approach, coupled with the paradigm of scientific medicine. The words "sexual option", "sexual choice" and "homosexualism" were often evidenced in the analysis, which suggests the understanding of diversity through biological, pathological and reductionist approaches. The strengthening of continuous and permanent teacher education becomes urgent and necessary. However, the contradictions also point to a programme that is alive, dynamic and in paradigmatic transition. There are possibilities of fully experiencing pedagogical processes of sexual education in an emancipatory approach.

KeYwords: Medical degree; Integrated curriculum; Medical training; Emancipatory sexual education; Teacher education 
¿OPCIÓN SEXUAL O ORIENTACIÓN SEXUAL? LA COMPRENSIÓN DE DOCENTES DE UN CURSO DE MEDICINA SOBRE SEXUALIDAD

\section{RESUMEN}

El artículo presenta una parte del resultado de un estudio que investigó la comprensión de docentes de un curso de Medicina sobre la dimensión humana de la sexualidad para desvelar procesos de educación sexual vividos en una propuesta de currículo innovador. La investigación ha sido orientada por el paradigma del materialismo histórico dialéctico que utiliza el método dialéctico para el análisis de la realidad. Los instrumentos de recolección de datos comprendieron los cuestionarios y las entrevistas. En el análisis de contenido se desvelaron contradicciones en la práctica pedagógica de los docentes que representan vivencias ancladas, principalmente, en la vertiente médico-biológica sumada al paradigma de la medicina científica. Se registró el uso frecuente de las palabras "opción sexual" y "elección sexual", además del término "homosexualismo", lo que sugiere la comprensión de la diversidad por enfoques biológicos, patologizantes y reduccionistas. El fortalecimiento de la formación continuada y permanente de los docentes se vuelve urgente y necesaria. Sin embargo, las contradicciones también apuntan a un curso vivo, dinámico $\mathrm{y}$ en transición paradigmática, donde hay posibilidades de vivenciarse con plenitud pedagógica procesos de educación sexual en un abordaje emancipatorio.
Palabras Clave: Graduación en Medicina; Currículo integrado; Formación médica; Educación sexual emancipatoria; Formación del profesorado 